\title{
Using Data Mining Methods to Explore the Important Factors of University Management from the Perspective of School Affairs Research
}

\author{
Ke-Fei Wu ${ }^{1 *}$, Ming-Chih Chen', Ben-Chang Shia ${ }^{2}$ \\ ${ }^{1}$ Graduate Institute of Business Administration, Fu Jen University, Taiwan \\ ${ }^{2}$ College of Management, Taipei Medical University, Taiwan \\ Email: ${ }^{*}$ kefei1523@gmail.com
}

How to cite this paper: $\mathrm{Wu}, \mathrm{K} .-\mathrm{F}$. , Chen, M.-C., \& Shia, B.-C. (2020). Using Data Mining Methods to Explore the Important Factors of University Management from the Perspective of School Affairs Research. American Journal of Industrial and Business Management, 10, 1473-1481. https://doi.org/10.4236/ajibm.2020.108096

Received: July 21, 2020

Accepted: August 23, 2020

Published: August 26, 2020

Copyright $\odot 2020$ by author(s) and Scientific Research Publishing Inc. This work is licensed under the Creative Commons Attribution International License (CC BY 4.0).

http://creativecommons.org/licenses/by/4.0/

\begin{abstract}
The management of colleges and universities is closely related to the rise and fall of the overall physical fitness of the school. How the leadership can rely on the operation of the evaluation mechanism to enable the school to build a good physical fitness in order to respond to the competitive situation of the education market, these must be carefully strategies for thinking and seeking solutions are also topics that researchers are interested in. The purpose of this research is to collect five major aspects of school affairs information including student, teaching, research, school affairs, and financial affairs from the Ministry of Education's university and college school affairs information disclosure platform, and use data exploration to analyze it. Discuss the characteristics of university management from the perspective of university evaluation indicators based on the analysis results. The number of colleges and universities in Taiwan is showing a downward trend. According to the establishment, there were 53 public colleges and 112 private colleges in Taiwan in 2012, and there were 48 public colleges and 104 private colleges in Taiwan in 2019. According to the types of schools, there were 74 general universities and 91 technical colleges in Taiwan in 2012, and there were 70 general universities and colleges in Taiwan in 2019. This research has established a school affairs research big data platform to help users quickly click and click to read the public information about the school affairs of the target school, as well as the introduction to the school in Wikipedia, except for the previous analysis. In addition to the data field of, the page for exploring public opinion of each school's Dcard has also been added to allow users to quickly understand the current content of topics discussed by students, as a reference
\end{abstract}


for school management.

\section{Keywords}

Institutional Research, Data Mining

\section{Introduction}

There are many environmental factors that affect the power of the education market, such as: the ratio of higher education to the total population, the substantial increase in the admission rate of higher education, and the arrival of the era of declining birthrates. Therefore, before the 1990s, the higher education market in Taiwan Demand exceeds supply. From the perspective of marketing operations, it is production-oriented, that is, using the mechanism of joint examinations, schools select students (seller market); Taiwan's economy recovered after the 1990s, coupled with the relaxation of education policies As a result, higher education institutions have changed and increased significantly. Schools have begun to implement multiple entrance channels to replace the traditional entrance exams. Not only can schools choose students, but the proportion of students choosing schools (buyer's market) has also increased significantly, forming a production Parallel to sales orientation.

The density of colleges and universities in Taiwan is the highest in the world, and Taiwan's higher education has been affected by reforms and liberalization, from the original elite education to universal education, but the booming education economy market environment has been impacted by many factors. For example, the number of colleges and universities has increased dramatically, the birth rate has fallen, the phenomenon of declining birthrates, the opening of the education market to foreign countries, and the prosperity of online education courses, etc., have caused disadvantaged technical colleges and newly established universities with insufficient enrollment to face unprecedented crises.

The school affairs database is a knowledge base that can accumulate the school management, and can also be an important asset to help the school in daily operations and making future decisions. Compared with primary and secondary schools, universities have a higher degree of autonomy in the development of school affairs; and the responsibility brought about by autonomy is that universities have to experience the influence of globalization and the competition between faculty and students and other universities in the world. Develop vigorously and cultivate outstanding talents. Therefore, universities must build and develop a school affairs database, collect data and analyze them so that they can be used as a reference and effectiveness evaluation when making decisions and implementing plans, and further accumulate, activate and make good use of organizational knowledge (Peng, 2013; Hossler, Kuh, \& Olsen, 2001; Nonaka, 1994). 
The main purpose of using school affairs database data for analysis is to hope that schools can make more use of existing resources and review the effectiveness of various resources invested. The results of data analysis can be used as a reference for management, such as: School management, decisionmaking, etc., and allows schools to enhance their own competitiveness and help the management to have more reference indicators in decision-making during self-examination. In addition, when higher education is facing difficulties, it can Lead the school forward and use it as a basis for self-improvement and problem solving.

The management of colleges and universities is closely related to the rise and fall of the overall physical fitness of the school. How the leadership can rely on the operation of the evaluation mechanism to enable the school to build a good physical fitness in order to respond to the competitive situation of the education market, these must be carefully Strategies for thinking and seeking solutions are also topics that researchers are interested in. What are the important factors in the indicators that school affairs researchers usually pay attention to that can reflect the status of university management? In addition, from the perspective of school affairs research, what help can you provide for university management? These are motivations for researchers to explore.

The purpose of this research is to collect five major aspects of school affairs information including student, teaching, research, school affairs, and financial affairs from the Ministry of Education's university and college school affairs information disclosure platform, and use data exploration to analyze it. Discuss the characteristics of university management from the perspective of university evaluation indicators based on the analysis results.

\section{Literature Review}

The development of higher education in Taiwan has been for some time. Not only does it have to face many competitors from other domestic colleges and universities. After joining the World Trade Organization in 2003, the education market has faced competition and challenges from foreign schools. Therefore, higher education in Taiwan. It is essential to enhance international prestige and create competitive advantages from the essence, such as: developing school characteristics, ensuring teaching quality, improving school management performance, etc. (Gai, 2002).

Higher technical schools should also demand students and society. More active review can establish the school's positioning, market segmentation, and development of key features. These are all methods for the school to operate sustainably (Yang, 2003). Lin (2003) said that school operators should think about how to Faced with the cruel business environment, such as how to effectively use funds in school affairs, how to improve the enrollment strategy, etc., these need to be addressed and resolved one by one.

Liu (2015b) stated that the financial and tuition reform policies of European 
higher education can enable Taiwan to realize two key points, namely: 1) European welfare countries have begun to revise the direction of higher education policies, gradually increasing higher education. The nature of public finances should be downplayed; 2) Limited to the government's financial resources, it is unlikely that the publicization of higher education will be implemented in Taiwan.

Liu (2015a) stated that the university organization includes administration, teachers and students, but will have different positions due to old experience, and there will be differences in the operation of the school. How to build consensus and find the right strategy is the sustainability of the school Therefore, for the important decisions of school development, it is necessary to break through the traditional model and adopt scientific basis to allow leaders to make correct judgments.

Zeng (2016) said that in recent years, Taiwan's colleges and universities and research institutes have encountered a serious shortage of enrollment. It would be very difficult to make predictions and understand the real reasons if they only rely on the educational administration information system. If the number of students enrolled per year is sufficient, the topic of enrollment data will never be mentioned. However, if the number of enrollments fluctuates greatly, the whole school will pay special attention to it. School funding and resources will be affected, and deans, department heads, and teachers will all become stakeholders. A lot of attention and research are needed to solve this dilemma. However, if we can combine the birth rate of the external population and the employment rate distribution of various industries, we can predict and explain the fluctuation of the data, and we can formulate a response plan in advance.

Jiang (2016) stated that school affairs research is an activity to investigate and analyze the effectiveness of running a school and its determinants. The purpose is to provide data and evidence required for school affairs decision-making. Its purposes include admission management, school affairs planning, financial management, and learning effectiveness evaluation. And self-evaluation.

$\mathrm{Fu}$ (2016) said that the WASC College Review Committee has selected senior analysts from the School Affairs Research Office as members of the external interview team to give evaluations and recommendations on the soundness of the school's research function in the school. It can be seen that school affairs research occupies a key position in the accreditation system of American universities; and most universities in Taiwan will use business concepts in the business field when they explain the self-improvement mechanism in the school, such as: PDCA (Plan, Do, Check, Act) quality control loop, but this self-improving data system does not seem to have much focus. Taiwan's promotion of university business evaluation has the following two problems: 1) The administrative burden caused by too many evaluation indicators and piled-up data 2) The objectivity and professionalism of the evaluators are questioned. In addition, one of the purposes of promoting university affairs evaluation is to allow universities to 
implement self-improvements, and finally achieve the results of university selfmanagement; school affairs research is not a new project in the school affairs evaluation, but To make up for the key factors that were lacking in the past to promote school affairs evaluation.

\section{Methodology}

In this study, the research concept and the proposed research theme are firstly developed. The research motivation and purpose are confirmed through preliminary literature collection, and then the relevant domestic and foreign literature related to the research problem and the discussion of the research are established to establish the conceptual framework of this research. Develop research propositions based on the structure (Figure 1), determine the research object and research design, collect and organize relevant resources, and finally analyze and solve the resources, and write a research report based on the results of the analysis.

This study was conducted to collect data for the entire public information platform and tertiary school to tertiary institutions as a unit, sorting out the "academic year", "School Name", "Do not set up", "School class", "Official enrollment number of students", "Number of students in school", "Number of students in school", "Subtotal of graduates", "Number of graduates", "Number of graduates", "New applications during the school year Subtotal of drop-outs", "Subtotal of total drop-outs by the end of the school year", "Subtotal of dropouts",

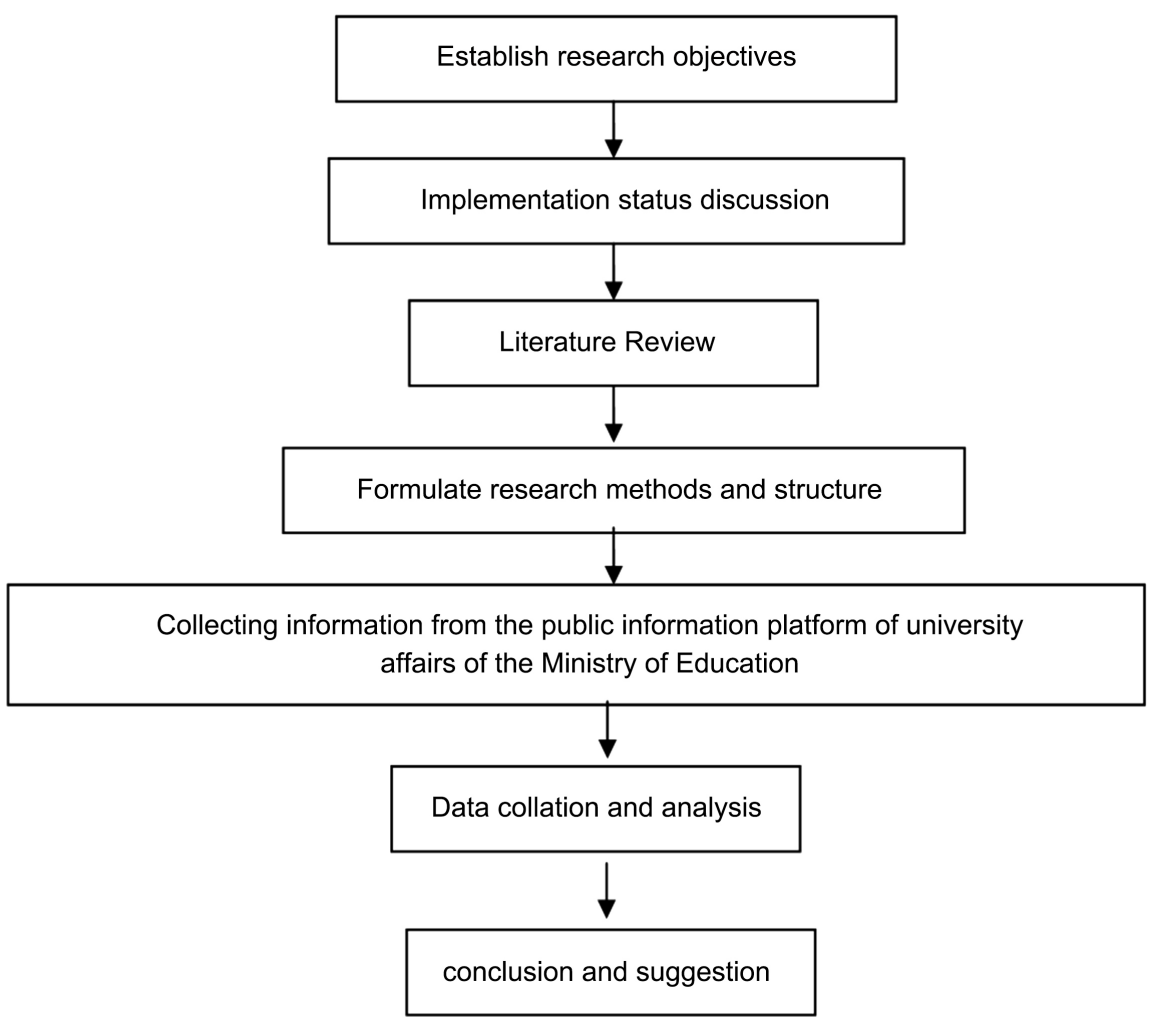

Figure 1. Study process. 
"New student registration rate", "Number of students in the day school system", "Full-time day teachers", "Daytime student-teacher ratio", "School statistics Department Code", "Number of Paper Books Collection (Volumes)-Chinese Paper Books-General Category", "Number of Paper Books Collection (Volumes)-Chinese Paper Books-Philosophy”, "Paper Book Collections "Number (Volumes)-Chinese Paper Books-Religious", "Paper Books Collection (Volumes)-Chinese Paper BooksNatural Science”, "Paper Books Collection (Volumes)-Chinese Paper BooksApplied Science", "Paper Books Collection (Volumes)-Chinese Paper BooksSocial Sciences", "Paper Books Collection (Volumes)-Chinese Paper BooksHistory and Geography (including World History) Land category)", "Paper book collection (volume)-Chinese paper books-language and literature", "Paper book collection (volume)-Chinese paper books-art", "Paper books Number of Collections (Volumes)-Foreign Language Paper Books", "Journal Bound Books (Not Cataloged by Paper Books) (Volumes)", “Amount of Electronic Materials Available-Online Database (Type)", "Electronic Materials Available Usage-CD and other types of databases (types)", "Useable amount of electronic data-Electronic journals (types)", "Useable amount of electronic materials-e-books (volumes)", “Audiovisual materials (pieces)", "Current Book (Type)-Newspaper (Type)", "Current Book (Type) Periodical-Chinese and Japanese (Type)", "Current Book (Type) Periodical-Western (Type)", "Library Service (Number of People)-Number of Seats for Reading Books", "Library Service (Number of People)-Number of Borrowing (only including paper books and non-book materials)", "Library Service (Number of People)-Number of Borrowing Books (only including Paper books and non-book materials)", "Library Service (Visit)-Online and CD-ROM Database (including e-books and e-journals) retrieval times", "Subtotal of the number of people staying in self-owned dormitories", "Number of people staying in self-owned dormitories" Columns such as "male", "females in self-owned dormitories", and "tuition and miscellaneous fees as a percentage of total income" are used for statistical analysis, data mining model establishment and information integration platform.

The research methods used in this study mainly include classification, estimation, clustering, correlation, and time series. The statistical analysis methods for classification and estimation are all decision trees. This study will use DATA MINING Excel Addin for analysis.

\section{Result}

According to the statistics shown in Table 1, overall, the number of colleges and universities in Taiwan is showing a downward trend. According to the establishment, there were 53 public colleges and 112 private colleges in Taiwan in 2012, and there were 48 public colleges and 104 private colleges in Taiwan in 2019. According to the types of schools, there were 74 general universities and 91 technical colleges in Taiwan in 2012, and there were 70 general universities and 82 technical colleges in Taiwan in 2019. If you consider the establishment of 
Table 1. The college number of institutions in each year.

\begin{tabular}{|c|c|c|c|c|c|c|c|c|c|}
\hline & 2012 & 2013 & 2014 & 2015 & 2016 & 2017 & 2018 & 2019 & Total \\
\hline General university & 74 & 73 & 73 & 75 & 76 & 70 & 70 & 70 & 581 \\
\hline Technical College & 91 & 91 & 88 & 87 & 87 & 87 & 83 & 82 & 696 \\
\hline private & 53 & 52 & 51 & 51 & 51 & 50 & 48 & 48 & 404 \\
\hline Public & 112 & 112 & 110 & 111 & 112 & 107 & 105 & 104 & 873 \\
\hline Public General university & 35 & 34 & 34 & 34 & 34 & 33 & 33 & 33 & 270 \\
\hline Public Technical College & 18 & 18 & 17 & 17 & 17 & 17 & 15 & 15 & 134 \\
\hline private General university & 39 & 39 & 39 & 41 & 42 & 37 & 37 & 37 & 311 \\
\hline private Technical College & 73 & 73 & 71 & 70 & 70 & 70 & 68 & 67 & 562 \\
\hline Total & 495 & 492 & 483 & 486 & 489 & 471 & 459 & 456 & 3831 \\
\hline
\end{tabular}

categories and school types at the same time, there were 35 public general universities, 18 public technical colleges, 39 private general universities and 73 private technical colleges in Taiwan. There are 33 public general universities, 15 public technical colleges, 37 private general universities and 67 private technical colleges.

As shown in Table 2, the part of the number of students enrolled in formal colleges in general universities was 9229.55 (standard deviation 6965.27) per school in Taiwan in 2012, and decreased to an average of 9190.57 (standard deviation 6716.51) per school in Taiwan in 2019; if the median is compared, it is 7524 (upper quartile 4760.25-lower quartile 12,312.25) in Taiwan in 2012, and decreases to 7062.5 (upper quartile 4470.75-lower quartile 11976.5) in Taiwan in 2019.

This study discusses the important factors of university management by using the method of data mining for public school affairs. This section uses the aforementioned data as the basis to establish a big data platform for school affairs research through $\mathrm{R}$ shiny, and visualize the data in the school affairs indicators on the platform, so that users and researchers can quickly understand the trend of change, And also use historical data to predict the situation in the next 5 years, and provide users as a basis for decision-making assistance. This section will introduce an overview of the various functional blocks of this platform and use the Youjiu Alliance as an example of operation.

Figure 2 is a diagram of the image structure of the research platform. By linking the data of various rooms in the school and the external public data, various structured and unstructured data can be obtained, and then the hidden data can be found through different data mining analysis methods. The important information in the data provides substantial decision support for university management. 
Table 2. The number of students enrolled in regular colleges in each year.

\begin{tabular}{cccccc}
\hline Year & Mean & SD & Mid & Min & Max \\
\hline 2012 & 9229.550 & 6965.270 & 7524.000 & 39 & 32,693 \\
2013 & 9287.790 & 6874.330 & 7397.000 & 53 & 32,168 \\
2014 & 9328.920 & 6851.620 & 7566.000 & 47 & 31,791 \\
2015 & 9197.650 & 6851.630 & 7504.000 & 12 & 31,758 \\
2016 & 8924.000 & 6938.330 & 7408.000 & 13 & 31,783 \\
2017 & 9535.710 & 6769.520 & 7399.000 & 267 & 31,802 \\
2018 & 9361.800 & 6696.340 & 7260.500 & 280 & 31,745 \\
2019 & 9190.570 & 6716.510 & 7062.500 & 305 & 31,945 \\
\hline
\end{tabular}

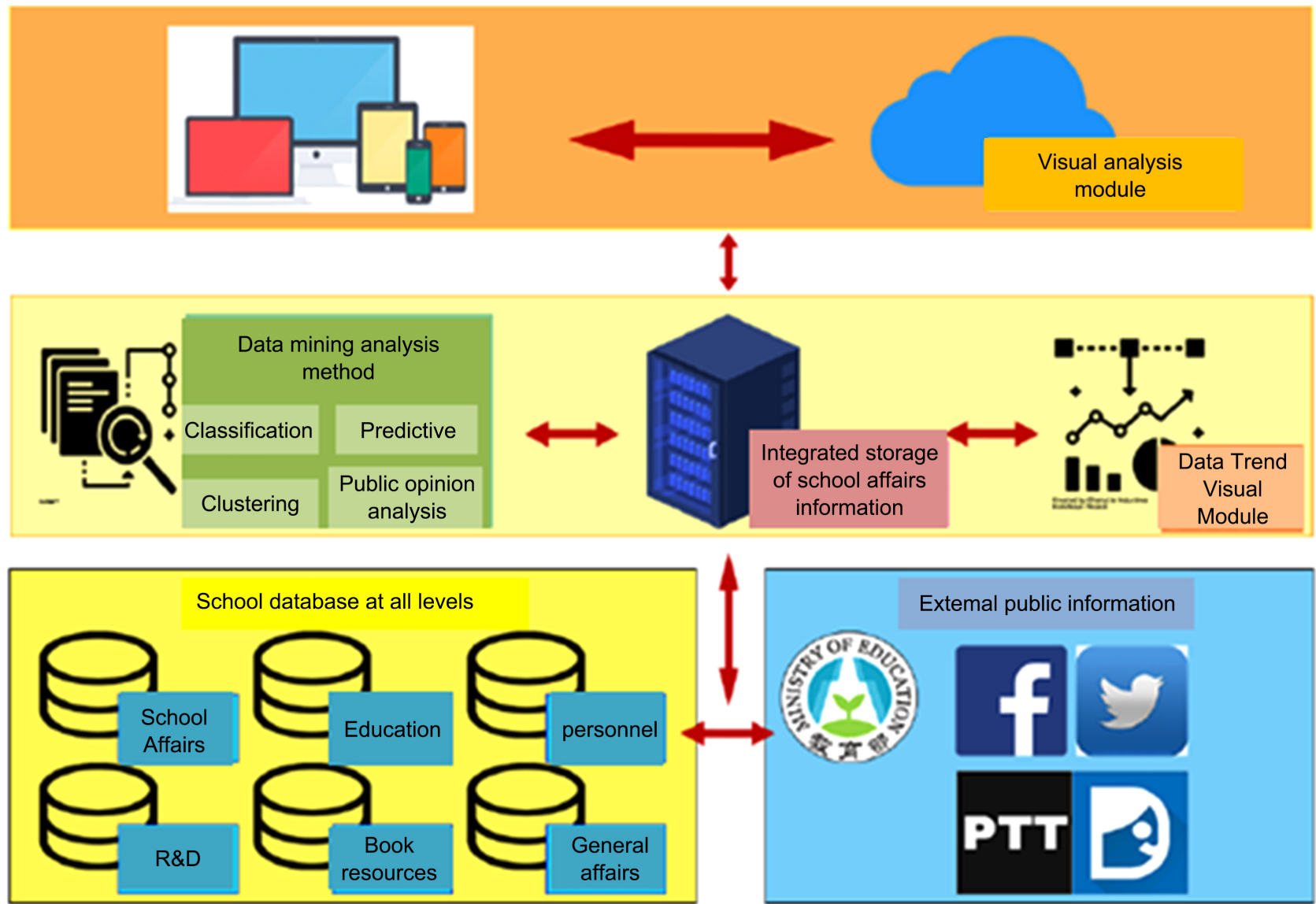

Figure 2. Platform architecture diagram.

\section{Conclusion}

This research reviews the literature of school affairs research in the past. Most of the past researches collected data through questionnaires or interviews, or used the more detailed database of a single school to conduct research, while the universities use public databases. Since it is the information submitted by each school to the Ministry of Education, compared with the school affairs research 
database of a single school, there are no more detailed variables that can be used, so the analysis of this research will be subject to many restrictions. However, the method of data mining and the spirit of big data research is to find out the relevance of data. Although this research is not the first time that the concept of using big data or data mining is proposed for the doctoral dissertation of school affairs, it is compared with past research. The previous research is not similar to this research to do a complete analysis and discussion of a large number of data and variables at one time, and combines the establishment of a data analysis platform. Therefore, it is recommended that follow-up researchers can refer to the analysis method of this study to do more in-depth analysis and research on the school affairs research database of a single school.

\section{Conflicts of Interest}

The authors declare no conflicts of interest regarding the publication of this paper.

\section{References}

Fu, Y. Z. (2016). School Affairs Research and University Affairs Evaluation. Evaluation Bimonthly, 60, 18-21.

Gai, Z. S. (2002). Education Management and Management. Taipei: Normal University Library.

Hossler, D., Kuh, G., \& Olsen, D. (2001). Finding Fruit on the Vines: Using Higher Education Research and Institutional Research to Guide Institutional Policies and Strategies. Research in Higher Education, 42, 211-221.

https://doi.org/10.1023/A:1026577604180

Jiang, D. L. (2016). Welcome the Advent of the Era of School Affairs Research. Evaluation Bimonthly, 60, 7-9.

Lin, T. J. (2003). The Characteristic Development of Higher Technical and Vocational Education. Technical and Vocational Education, 83, 40-46.

Liu, X. X. (2015a). Use Data Analysis as a Strategy for Enrollment in College Sports Related Departments. College Physical Education, 133, 7-13.

Liu, X. X. (2015b). The Changes and Controversies of University Finance and Tuition Policies in the Process of National Transformation-The Enlightenment of European Experience to Taiwan. Higher Education, 10, 37-71.

Nonaka, I. (1994). A Dynamic Theory of Organizational Knowledge Creation. Organization Science, 5, 14-37. https://doi.org/10.1287/orsc.5.1.14

Peng, S. M. (2013). The Concept and Application of Higher Education School Affairs Research. Taipei City: Higher Education Press.

Yang, C. X. (2003). The Comparison and Prospect of the Development of Technical and Vocational Education in China and the United States. Technical and Vocational Education, 80, 39-45.

Zeng, Y. X. (2016). The Construction, Analysis and Application of the School Affairs Research Database. Contemporary Educational Research Quarterly, 24, 107-134. 